\title{
Service quality of school canteens: A case study from the Western Province, Sri Lanka
}

\author{
M.C. Weerasinghe ${ }^{1}$, Samanthi Bandara ${ }^{2}$, M. Sanoon ${ }^{3}$ \\ ${ }_{2}^{1}$ Department of Community Medicine, Faculty of Medicine, University of Colombo, Sri Lanka. \\ Institute of Policy Studies of Sri Lanka (IPS), Colombo, Sri Lanka. \\ ${ }^{3}$ Base Hospital, Karawanella, Sri Lanka.
}

\author{
Article Information \\ Total number of \\ Words 3062 \\ Tables 04 \\ Authors have no conflicts of interest \\ to declare \\ Keywords: School Health, Health \\ policy, Service quality, School canteens \\ Date of submission: 22.05 .2017 \\ Date of acceptance: 03.08.2017 \\ DOI: \\ http://doi.org/10.4038/cjms.v54i2.4817 \\ Author responsible \\ for correspondence: \\ Ms. Samanthi Bandara, \\ Research Officer, \\ Institute of Policy Studies of Sri Lanka, \\ 100/20, Independence Avenue, \\ Colombo 7. \\ Samanthi@ips.lk
}

http://orcid.org/0000-0003-0339-3738

\begin{abstract}
Background:

Creating a healthy eating environment in schools is a proposed outcome of school canteen guidelines issued in 2007 in Sri Lanka. Maintaining service quality, guarantees achieving better health standards of school canteens.
\end{abstract}

\section{Objectives:}

This study assessed service quality of canteens in terms of location, physical facilities in food preparation and serving areas, food handling practices, food storage, and waste management. Further, it explored causes for deviating the service quality from the stipulated guidelines.

\section{Methods:}

This is a across sectional study, conducted in government schools in two districts in 2014. Service qualities of the canteens were assessed using a quantitative tool. Qualitative inquiry was used to explore perceptions of school principals and canteen operators on service quality.

\section{Results:}

Eighty eight percent of canteens were located in a suitable place and 78\% had a clean outside environment. Only two third of food preparation areas satisfied the basic criteria. A dining area was available for students only in half. More than $80 \%$ of canteens had waste water drainage and $89 \%$ of canteens had bins for waste disposal. However, majority of canteens did not keep bins closed. Half of the canteens had cooling equipment, and majority of them had a practice to store raw materials and cooked food separately. Almost in $30 \%$ of canteens, food was not covered in the serving area, and more than $90 \%$ of canteens used neither aprons nor gloves.

\section{Conclusion:}

This study found that providing quality food quality in school canteens has been a challenge due to many gaps in the present system. However, strengthening the service quality towards a healthy nutrition promoting setting can be done by change in planning and implementation processes.

\section{Background}

Constant attempts on improving school children's nutritional status by successive governments in Sri Lanka implies nutrition of school children as a national priority $[1,2]$. Creating healthy eating environment within the school premises using existing school canteens is one of the national exertions.
For this a national policy was drafted in 2006 to formalize the functioning of school canteens. Providing nutritious, culturally acceptable food at affordable prices, ensuring food hygiene, promoting healthy dietary habits, child friendly service provision, improving facilities of school canteens were expected through this policy. 
Following the draft of the policy, two circulars, one in 2007 (Ministry of Education circular 2007/2), and a follow up circular in 2011 (Ministry of Education circular 2011/3) were issued to streamline the functions of the initiative. In these circulars, hygienic preparation of food, food safety, ensuring appropriate nutritional value, enhancing healthy food habits, maintaining a clean indoor and outdoor environment, maintaining proper storage facilities, improving opportunities to buy healthy foods from the canteen, prohibiting unhealthy food were prominent measures taken to ensure service quality of school canteens.

Assessment methods for service quality emanate from international obligations and experiences during the last two decades. A resolution of World Health Assembly 57.17 was declared by the World Health Organization in 2004, [3] by which food related initiatives across the world were guided towards establishing healthy food settings. School healthy food and drink policy of West Australia in 2012 [4], and National Healthy School Canteens Guidelines by the Australian Government in 2010 [5] were two examples of national recognition in Australia on quality of school canteens.

As a conceptual basis, the RATER service quality model [6] is used to measure the service quality even in food establishments [7]. Out of five dimentions of the RATER model, two dimentions; tangible, and assuarance, are relevant to this study in order to evaluate the service quality of school canteens. Mitchella, Fraserb and Bearonb (2007) [8] emphasized that unsafe food handling practices considarably contribute towards spreading foodborne diseases. The authors used the "PRECEDEPROCEED" model, which was developed by Green and Kreuter [9], to identify the ecological and individual factors on safe food handling behaviours, of which, availability of appropriate equipment and space (e.g. necessary tools, water and hand washing area, adequate space for preparations, dining chairs and table, interior designing etc.) is identified as an enabling factor towards ensuring food safety and hygiene. This is further recommended by Rennie (1995) [10]. He stated that availability of equiepment, physical layout for the operations, and physical infrastructure for handwashing can support to improve safe food handling practices in the food establishments.

In oder to sustain the desired outcome of safe food handling practices, the tangible dimention should be coupled with knowledge and skills of the food handlers (assuarance dimention). As Zain and Naing (2002) [11] emphasized, the food handlers should be trained in terms of knowledge, attitudes, and practices (KAP) towards reducing food-born diseases and ensuring food safety. Further, evaluating such training programmes is essential to examine the effectiveness of given training particulalrly because the majority of the food handlers are with low education status [11]. The World Health Report emphasized that training for food handlers should be included the basic principles of food safety namely, skills and practices on food storage, food contamination, and temperature control [12]. Further, improtance of providing safe food handling instruction at the begining to food handlers' is highly recognized [8].

In Sri Lanka seven years has passed since the implementation of school canteen guidelines. However, a systematic assessment of the implementation of the proposed policy and the circular has not yet been done. Such an assessment would provide valuable evidence for improvement of status of school canteens. Objective of this study was to assess the service quality of school canteens in the Western province of Sri Lanka in terms of five aspects namely, location, physical facilities in food preparation and serving areas, food handling practices, food storage, and waste management.

\section{Ethics Statement}

This is an attempt to evaluate the extent to which the school canteen guidelines are implemented in two districts. This study does not intend to assess or report performance of individual schools, educational divisions or educational zones. All the information collected was kept confidential under the principal investigator. No identification information is disclosed or reported. The study obtained ethics approval from the ethics committee of the University of Colombo, and permission from the Ministry of Educational Services.

\section{Methods}

This is a cross sectional study, conducted in government schools in two districts in the Western province of Sri Lanka. For general administrative and resource allocation purposes, the education system is divided into 3 levels namely, districts, zones, and finally divisions. We selected two districts out of the three in the Western province of Sri Lanka. Schools are categorized into 4 types Type 1AB, Type 1C, Type 2, and Type 3 -according to the educational stream and number of grades in a school. Multistage stratified sampling method was adopted to select adequate representation of schools in the two districts. Therefore, using simple random sampling, two educational zones of each district of Colombo and Gampaha were selected, and the same method was followed to choose two educational divisions from each of the selected educational zones. Finally, four educational zones and eight educational divisions from both districts were selected. Considering the types of schools as the 
"stratum', three schools were selected from each stratum. Type 3 schools were excluded as they are small schools with few students. Accordingly, nine schools were chosen from one division, and the final sample consisted of 72 schools (9 schools* 8 divisions). When the schools have more than one canteen, the canteen used by the most number of students was selected for the assessment.

Maintaining service quality according to the guidelines was assessed quantitatively using a pretested checklist. The checklist included location, physical facilities in food preparation and serving areas, food handling practices, food storage, availability of safe drinking water, and waste management. The checklist was developed considering the directions in the guidelines issued to schools and the techincal details specified in the Food Act of 1980 [13] and the regulations. Perceptions on adherence to the guidelines were explored via in-depth interviews with school principals and canteen owners, using a flexible interview guide. Interviews were focused to obtain perceptions on the implementation of guidelines at present, particularly focusing on challenges faced in the implementation. Considering the type of school, medium of instruction, and the status of the canteen during the preliminary observations, twelve schools for in-depth interviews were selected. Further, data collectors and investigators recorded their additional observations in field notebooks.

Data collection was done during month of September in 2014. To prevent possible bias, no prior notification was given regarding the day of inspection or the exact nature of data collection. Quantitative data was analyzed according to adherence or non-adherence for a given parameter of quality and presented as counts and percentages. All in-depth interviews were transcribed and transcripts were coded by two investigators independently and codes were finalized with consensus. Emerging themes were captured through an iterative process of re-cording, displaying, reducing and interpreting the data.

\section{Results}

Findings of this study are presented as descriptive statistics for quantitative data, and findings of indepth interviews. Descriptive statistics with regard to service quality are presented in terms of location, physical facilities in food preparation and serving areas, food handling practices, food storage, and waste management.

Of the 72 schools studied, only 68 schools maintained a canteen. Of those, $88 \%$ were located in suitable places away from toilets, garbage pits or other unhygienic surroundings. Though $78 \%$ of canteens had a clean outside environment, presence

CJMS 2017; 54(2):11-16 of animals outside the environment was observed in one fourth of canteens.

As Table 1 illustrates, only 54 (79\%) canteens prepared any kind of food inside the canteens. Forty eight percent of them prepared all types of food i.e. main meals, short eats, and drink (hot or cool).

Table 1: Type of food prepared at the canteens $(n=54)$

\begin{tabular}{lc}
\hline Type of food & Frequency (\%) \\
\hline Main Meals/ short eats/ drinks & $26(48.1)$ \\
Short eats and drinks only & $16(29.6)$ \\
Drinks only & $12(22.2)$ \\
\hline
\end{tabular}

Adequate space for food preparation was not observed in majority of the canteens (61\%) as indicated in the guidelines (Table 2). However, status of cleanliness of boundary wall in food preparation area, adequacy of lighting and ventilation were satisfactory in majority. Table 3 further illustrates facilities available for maintaining food safety within food preparation area.

Table 2: Facilities available at food preparation area $(n=54)$

\begin{tabular}{lccc}
\hline Facility & \multicolumn{2}{c}{ Availability } \\
\cline { 2 - 3 } & \begin{tabular}{c} 
Yes \\
\cline { 2 - 3 }
\end{tabular} & $\begin{array}{c}\text { Frequency } \\
\mathbf{( \% )}\end{array}$ & $\begin{array}{c}\text { Frequency } \\
\mathbf{( \% )}\end{array}$ \\
\hline Adequate space & $21(38.9)$ & $33(61.1)$ \\
Presence of ceiling & $12(22.2)$ & $42(77.8)$ \\
Clean wall & $38(70.4)$ & $16(29.6)$ \\
Adequate ventilation & $36(66.7)$ & $18(33.3)$ \\
Adequate lighting & $40(74.1)$ & $14(25.9)$ \\
Type of floor - Cemented & $49(90.7)$ & - \\
& $5(9.3)$ & - \\
Clean floor & - Tiled & $30(55.6)$ & $24(44.4)$ \\
\hline
\end{tabular}

Table 3: Facilities for maintaining food safety in the food preparation area $(n=54)$

\begin{tabular}{|c|c|c|}
\hline \multirow[b]{2}{*}{ Facility } & \multicolumn{2}{|c|}{ Availability } \\
\hline & $\begin{array}{c}\text { Yes } \\
\begin{array}{c}\text { Frequency } \\
(\%)\end{array}\end{array}$ & $\begin{array}{c}\text { No } \\
\text { Frequency } \\
(\%)\end{array}$ \\
\hline Utensils in usable condition & $36(67)$ & $18(33)$ \\
\hline Cleanliness of utensils & $29(54)$ & $25(46)$ \\
\hline $\begin{array}{l}\text { Working surface in good } \\
\text { condition }\end{array}$ & $27(50)$ & $27(50)$ \\
\hline Facilities to disinfect utensils & $26(48)$ & $28(52)$ \\
\hline $\begin{array}{l}\text { Hand washing facility in } \\
\text { food preparation area }\end{array}$ & $44(82)$ & $10(19)$ \\
\hline $\begin{array}{l}\text { Water supply availability at } \\
\text { food preparation area }\end{array}$ & $51(94)$ & $3(6)$ \\
\hline $\begin{array}{l}\text { Detergents are kept away } \\
\text { from food handling area }\end{array}$ & $41(76)$ & $13(24)$ \\
\hline $\begin{array}{l}\text { Light bulbs placement over } \\
\text { food handling area }\end{array}$ & $14(26)$ & $40(74)$ \\
\hline $\begin{array}{l}\text { Toilet is away from food } \\
\text { handling area }\end{array}$ & $51(94)$ & $3(6)$ \\
\hline $\begin{array}{l}\text { Presence of animals inside } \\
\text { food preparation area }\end{array}$ & $12(22)$ & $42(78)$ \\
\hline
\end{tabular}


(94.4\%), hand washing facility (82\%) and locating toilets further away from food handling area (94.4\%). However, only half of the canteens were able to allocate a dining area for students inside the canteen premises.

Facilities available in the food serving area are important to attain the service quality of the canteen. Food was not covered as a practice in 20 canteens (29.4\%). Further, food handlers in 94\% and 97\% of canteens did not use aprons or gloves respectively. About $57 \%$ of canteen workers served food with their bare hands (Table 4).

Table 4: Facilities available in the food serving area in the canteen $(n=68)$

\begin{tabular}{|c|c|c|}
\hline \multirow{3}{*}{ Facility } & \multicolumn{2}{|c|}{ Availability } \\
\hline & Yes & No \\
\hline & $\begin{array}{c}\text { Frequency } \\
(\%)\end{array}$ & $\begin{array}{l}\text { Frequenc } \\
\text { y (\%) }\end{array}$ \\
\hline Prepared food kept covered & $48(70.6)$ & $20(29.4)$ \\
\hline $\begin{array}{l}\text { Separate spoon for } \\
\text { different foods }\end{array}$ & $21(30.9)$ & $47(69.1)$ \\
\hline $\begin{array}{l}\text { Availability of reusable } \\
\text { dishware and cutlery }\end{array}$ & 38 (55.9) & $30(44.1)$ \\
\hline $\begin{array}{l}\text { Clean reusable dishware } \\
(\mathrm{n}=38)^{*}\end{array}$ & $33(86.8)$ & $5(13.2)$ \\
\hline $\begin{array}{l}\text { Availability of non- } \\
\text { reusable dishware }\end{array}$ & $26(38.2)$ & $42(61.8)$ \\
\hline Price list displayed & $29(42.6)$ & $39(57.4)$ \\
\hline $\begin{array}{l}\text { Clean food packing } \\
\text { materials }\end{array}$ & 36 (52.9) & $32(47.1)$ \\
\hline
\end{tabular}

Even though, only half of the canteens had a clean area to store raw materials, majority (59\%) refrained from keeping raw materials on the bear floor. Few canteens had a freezer (16.7\%) while majority (26 canteens) had a refrigerator. More than $90 \%$ of canteens were able to keep the cooling equipment clean. Out of these 26 canteens, 18 stored meat and dairy products separately while 20 kept cooked food and raw materials separately. The study observed $80 \%$ of canteens managing waste disposal properly. Almost $90 \%$ used bins for disposal, however $77 \%$ of them kept the bins open.

\section{Qualitative inquiry}

In-depth interviews evaluated reasons for deviation from the stipulated guidelines for maintaining service quality. Most of the schools did not have a building specifically built to house the canteen. Instead, in many schools, classrooms had been transformed into a canteen by mere supply of water, electricity and a waste water line. The principals indicted that they were unable to expand space and facilities in the canteens due to inadequate funds from education authorities. Their only means was support from parents and well-wishers. However, most schools struggle to solicit continuous support from parents. Parents coming from middle to low income communities find it difficult to finance school development activities on a long term basis. The schools were also unable to provide other basic necessities such as utensils for food preparation, food storage facilities, and dining facilities. Canteen operators had to organize all activities within the given space, bring their own furniture, food serving and cooking utensils, food storage showcase, cupboards, and cooling equipment. No proper mechanism was available within the existing system to assess and inspect the used utensils and whether the equipment met the standards stated in food legislation in the country. Therefore, usage of unsuitable and unclean utensils for food preparation and storage of cooked food, and raw materials contravening to the provisions of food Act of 1980

[13] could be attributed at least partly to poor provision of adequate facilities.

Less than fifty per cent of canteens provided adequate space for dining however, in most no seating facility was provided. Only teachers were provided a tiny space with a table and few chairs in some canteens. They believed it to be an obligation. However, the canteen operator did not consider providing this facility to students as an obligation. According to canteen operator, providing a dining area with seating facilities was beyond their mandate. The current system did not provide opportunity for educating the canteen owners on food safety, and proper food handling practices. Therefore, ability to maintain appropriate standards of hygiene was compromised.

All the principals stated that their involvement in the process of selecting a canteen operator is minimal. Principals can contribute only by appointing a committee or an in-charge teacher to supervise the canteen. When canteen operators violate the guidelines in food safety and hygiene, the principals face the difficult situation of deciding either to close the canteen and request the education authorities to appoint a new contractor or continue with the same contractor overlooking the violations. Appointing a new contractor takes a considerable time leading to closure of the school canteen. Principals also admit that complying with the canteen guidelines fully in the present circumstances is very difficult due to non-provision of basic requirements by the responsible authorities.

\section{Discussion}

This study found many challenges that prevent the school canteens from adhering to stipulated guidelines for food safety. Absence of space, equipment, and proper food handling practices were some of the obstacles. Since, most schools do not have a designated place, canteen operators were 
often given an abandoned classroom with few furniture to run a canteen. As per the RATER Model [6], availability of adequate physical and human resources is crucial to ensure service quality of a food establishment. The same is stressed by Mitchella, Fraserb, \& Bearonb (2007) [8] and Rennie (1995) [10]. According to these authors, use of appropriate equipment improves safe food handling practices, and it can be further improved by maintaining an appropriate physical layout of the operations. Allwood, Jenkins, Paulus et.al. (2004)

[14] revealed that adequate physical space increases the chance of improving hand washing practices.

Assurance dimension is another key contributor towards ensuring service quality of a food establishment [6]. According to the RATER model, said dimension can only be achieved by improving knowledge and skills of food handlers. Food handlers and their practices cannot be disregarded since they play a crucial role in food establishments. Mitchella, Fraserb, \& Bearonb (2007) [8] stressed that unsafe food handling practices is a key contributor to food-borne diseases. They stated that hand washing, preventing cross contamination, avoiding working while sick and proper storage (e.g. heating, cooling) practices were key tasks related to safe food handling practices. Pre-disposing, enabling, and reinforcing factors influence these practices. A satisfactory level of awareness among food handlers predisposes them to align with good practices. There is no process in the current setup to assess the level of knowledge among canteen operators or food handlers before awarding the contract nor a proper mechanism to provide training to canteen operators.

Appropriate equipment and physical spaces are two key contributors for improving the quality of services. Similarly, we observed three key obstacles that hinder provision of quality services. Authority for expanding the physical space is beyond the mandate of the canteen operator. They have to operate the canteen within the facilities provided. Even though some of the canteen operator are allowed to bring basic kitchen utensils, cutleries, and other equipment (e.g. refrigerator, cupboards, food storage and handling equipment), majority are not financially capable to invest on those. As per the current system, any person can bid for the school canteen tender. A bidder is selected solely based on quoted value of the tender. No prior criteria need to be met by the bidders at all. Even after selection, capacity and suitability of awardee for the purpose is not assessed. In addition, there is no institutionalized systematic mechanism to reinforce the behavior of canteen operators and food handlers on a regular basis. Monitoring the process is left to the individual school principal who has little or no competency in food safety assessment. As Mitchella, Fraserb, \&
Bearonb (2007) [8] pointed out, reinforcing factors are the last opportunity that influence the food handlers towards safe food handling practices by providing incentives, and changing co-workers' and management's attitudes. However, it is hard to expect this to happen within the current system. Achieving quality service at school canteens is not straightforward as RATER model [6] has prescribed. Therefore, the intended guidelines can be implemented smoothly to deliver a quality services only if prerequisites mentioned above are adequately met.

It was only possible to do a single observation in a given school due to logistic reasons. This could be seen as a limitation in our method. However, selection of uninform random days for observation reduced potential bias in relation to variations in the food availability and food handlers' behavior in school canteens.

\section{Conclusion}

Availability of adequate and quality physical and human resources is crucial to ensure quality service of a food establishment. This study found that system gaps in school canteen management hinder provision of good quality service. Essential facilities provided by the school for running a canteen is very minimal. Although school canteen operators are allowed to bring their own equipment, lack of proper housing and space prevent improvement of the quality of services. Identified gaps can be addressed through proper planning and implementation. Education authorities need to realize the importance of school canteens as a place of potential health promotion among school children.

\section{Acknowledgement}

Authors wish to thank the UNICEF for the financial assistance.

\section{References}

1. Ministry of Healthcare and Nutrition. National Nutrition Policy of Sri Lanka. Colombo: Ministry of Healthcare and Nutrition 2010.

2. National Nutrition Council. Vision 2016: Sri Lanka, A Nourished nation - Multi-sector action plan for nutrition. Colombo: National Nutrition Secretariat 2013.

3. World Health Organization. Global Strategy on Diet, Physical Activity and Health: $57^{\text {th }}$ World Health Assembly WHA57.17. Geneva: WHO 2004. www.who.int/dietphysicalactivity/strategy/eb1134 4/strategy english web.pdf(accessed 31 Dec 2014).

4. Pettigrew S, Pescud M, Donovan RJ. Outcomes of the West Australian school healthy food and drink policy. Nutr Diet 2012;69:20-5. 
5. Department of Health. Australian Government. 2010 National Healthy School Canteens Guidelines. Austrailia: Department of Health 2013.:www.health.gov.au/internet/main/publishing .nsf/Content/phd-nutrition-canteens (accessed 04 May 2017).

6. Zeithaml V, Parasuraman A, Berry L. Delivering Quality Service: Balancing Customer Perceptions and Expectations. New York: The Free Press 1990.

7. Mind Tools Editorial Team. Mind Tools.https://www.mindtools.com/pages/article/rat er.htm [accessed 21 Jan 2016].

8. Mitchella ER, Fraserb MA, Bearonb BL. Preventing food-borne illness in food service establishments: Broadening the framework for intervention and research on safe food handling behaviors. Int J Environ Health Res 2007;9-24.

9. Green L, Kreuter M. Health program planning: An educational and ecological approach. 4th edition. New York, NY: McGraw-Hill 2005.
10. Rennie M. Health education models and food hygiene education. J R Soc Promot Health 1995; 115:75-9.

11. Zain MM, Naing NN. Sociodemographics and KAP of Food Handlers. Southeast Asian j Trop Med Public Health 2002;33:410-17.

12. World Health Organization. The World Health Report: Life in the 21st Centuary: A vision for all. Geneva: WHO 1998.

13. Ministry of Health. Food Act, No 26 of 1980. Colombo: Ministry of Health 1980.

14. Allwood P, Jenkins T, Paulus C, et.al. Hand washing compliance among retail food establishment workers in Minnesota. J Food Prot 2004;67(12):2825-2828. 